\title{
OPTIC NERVE COMPRESSION BY AN INTRACANALICULAR MENINGIOMA*
}

\author{
BY \\ MICHAEL D. SANDERS AND MURRAY A. FALCONER \\ Guy's-Maudsley Neurosurgical Unit, London
}

THE diagnosis of progressive unilateral visual failure, when occurring as a solitary symptom in association with a visual field defect and when all routine investigations are negative, presents many difficulties. Amongst the conditions to be considered are retinal vascular disease, chronic simple glaucoma, atypical forms of toxic amblyopia, optic neuritis, and optic nerve compression. Meadows (1949) considered that a progressive unilateral visual failure associated with a scotomatous or sector field defect was highly suspicious of intracranial optic nerve compression and merited surgical exploration. The diagnostic problem presented by the case which is now being reported was one of unilateral visual deterioration associated with a centrocaecal scotoma, but with negative findings from all other investigations. It was resolved at craniotomy when a meningioma the size of a grain of wheat was removed from the intra-canalicular portion of the dural sheath of the right optic nerve. Cushing and Eisenhardt (1938) stated that "there has been no indubitable example of a sheath meningioma in which intact nerve has been found on both anterior and posterior aspects of a centrally disposed tumour spindle". The present case, however, is such an example and furthermore is one of the smallest tumours of the optic nerve ever recorded.

\section{Case Report}

A single woman aged 39 years was referred in 1952 by Dr. S. Behrman with a 7-month history of progressive visual failure in the right eye. She had first noticed this whilst reading in bed one night. There were no other symptoms apart from a headache in the region of the vertex which had lasted one day and had been accompanied by nausea, but no vomiting. Over a period of 4 months her vision had deteriorated from $6 / 18$ to $6 / 60$.

Examination.-She was a cheerful healthy woman, with no evidence of hypopituitarism. Routine physical examination was normal. The blood pressure was $120 / 80$, carotid pulsations were normal, and no cephalic bruit was heard. The ocular movements were full, there was no exophthalmos, and pupillary reactions were normal. The visual acuity was counting fingers in the right eye and $6 / 6$ in the left. The fundi showed a moderate degree of pallor of the right disc but the left disc was normal. Quantitative perimetry demonstrated a large centro-caecal scotoma in the right visual field, but the peripheral field was full to a $10 \mathrm{~mm}$. object (Fig. 1, overleaf).

The remaining investigations were normal. These included $x$ rays of the skull and optic foramina, right and left carotid arteriograms, and an air encephalogram. The lumbar cerebrospinal fluid (cells -0. protein $40 \mathrm{mg}$. per cent., pressure $125 \mathrm{~mm} . \mathrm{H}_{2} \mathrm{O}$ ) and the serum Wassermann reaction were normal. 


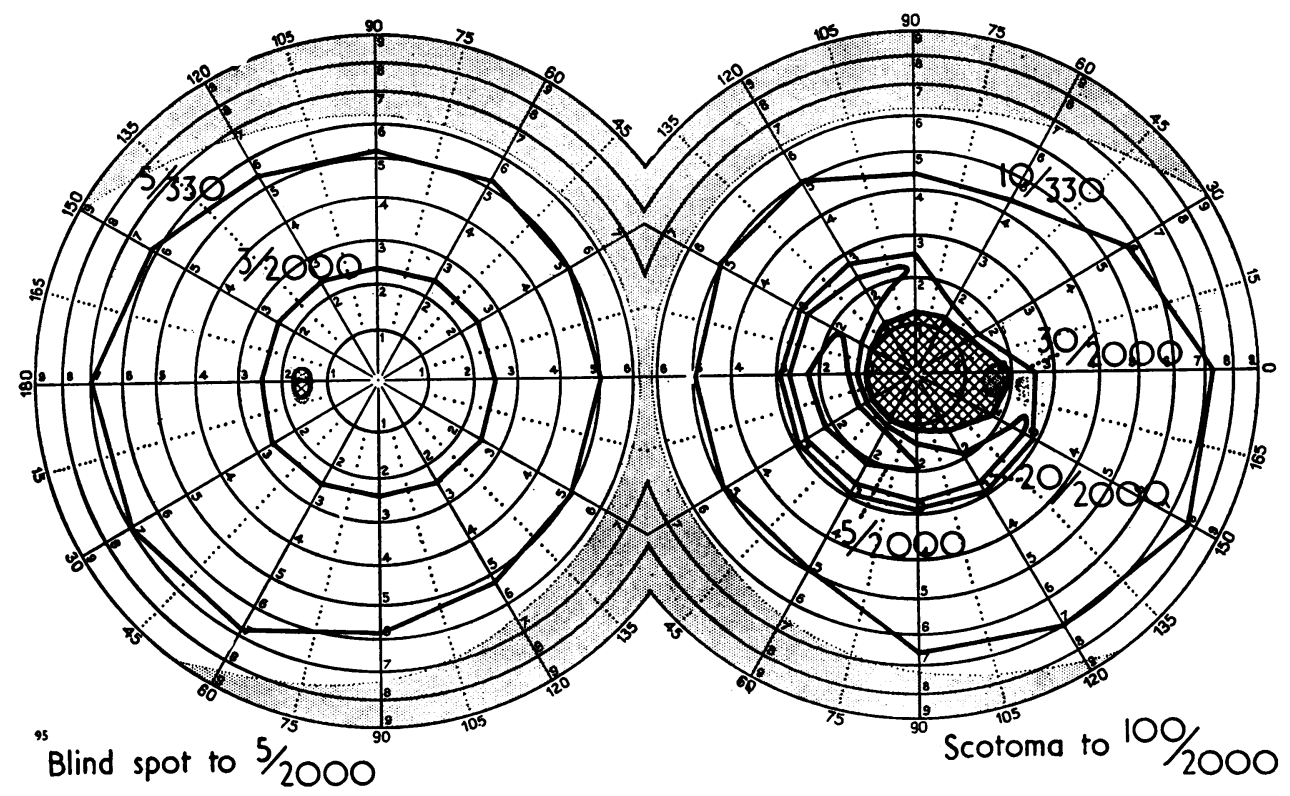

FIG. 1.-Pre-operative visual fields.

First Operation.- - In spite of these normal investigations, the progressive nature of the condition was considered a justification for exploration. A right frontal craniotomy was performed (M.A.F.) and the frontal lobe elevated. The optic nerves and chiasma appeared normal and so it was decided to explore the orbit. The dura along the lesser wing of the sphenoid was then incised centrally towards the optic canal. This manoeuvre exposed a small fringe of reddish brown tissue about $4 \mathrm{~mm}$. in height projecting inwards from the optic canal, and a biopsy was taken.

Second Operation.-10 days later, as the histological report indicated a meningioma, the frontal flap was re-opened and the roof of the orbit was removed as in the Naffzigger operation. The optic canal was also unroofed to expose a rather thickened dural sheath. This was incised and a small conical tumour measuring $6 \times 4 \mathrm{~mm}$. came into view. The tumour appeared to invaginate the optic nerve in the upper lateral quadrant and after removal a small depression in the optic nerve remained (Fig. 2, and Fig. 3, opposite).

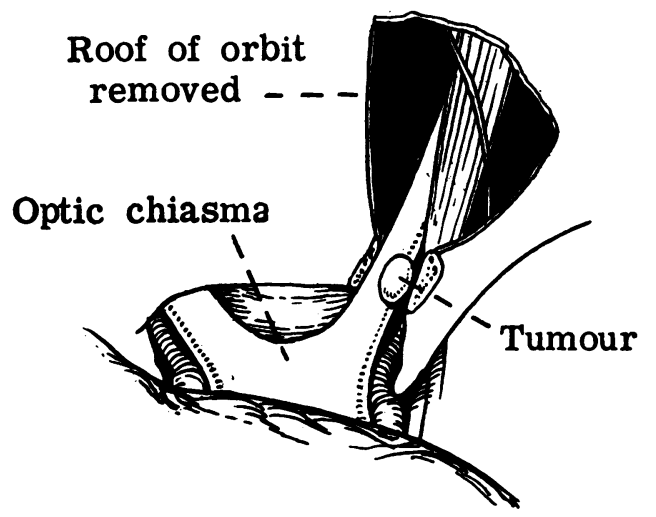

FIG. 2.-Operative sketch elaborated from surgeon's diagram, showing position of tumour after unroofing the right orbit.

Pathology._-"The minute fragment of tumour tissue is attached to one surface of the dura but does not penetrate it. The tumour consists mainly of spindle-shaped cells of uniform appearance 

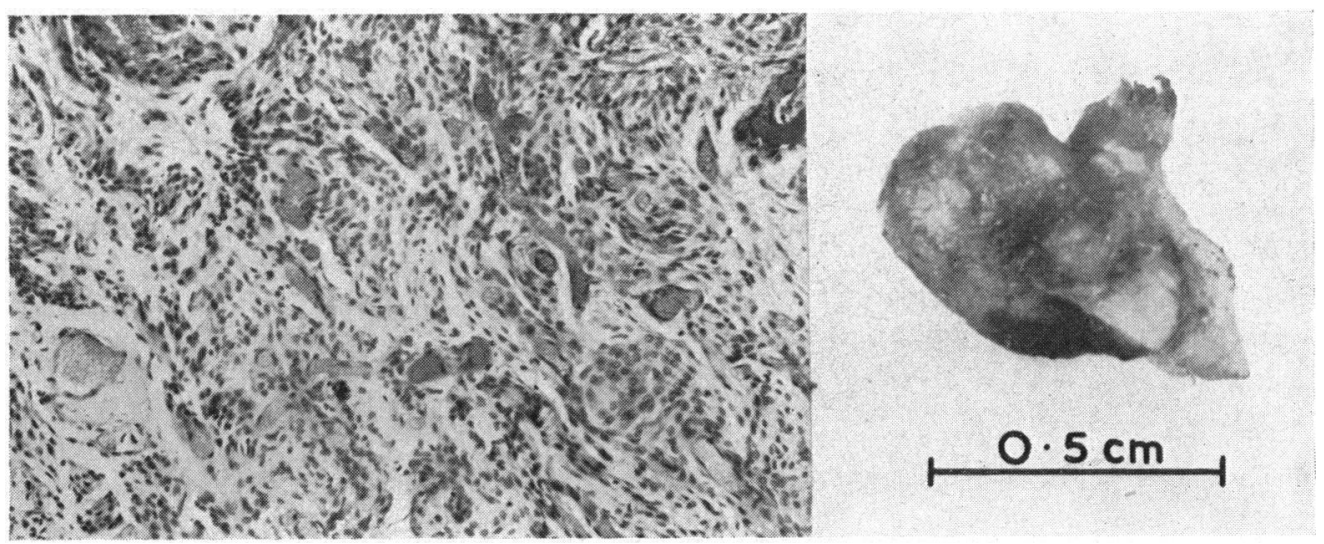

FIG. 3(a). Microscopic appearance. Haematoxylin and eosin. $\quad \times 115$.

FIG. 3(b). Macroscopic appearance of tumour.

tending to be arranged in whorls. Many plump endothelial cells are present. There is a considerable formation of reticulin fibres but little collagenous tissue and no psammoma bodies are seen. A noticeable feature is the large number of thin-walled blood vessels and blood spaces which vary considerably in size. Diagnosis-endotheliomatous meningioma".

Post-operative Course.-Recovery was uneventful (Fig. 4). The visual acuity in the right eye remained the same, but there was some slight improvement in the degree of density of the centro-caecal scotoma.

Follow-up.-Examinations at intervals over the past 10 years have shown no deterioration, suggesting that the tumour has not recurred. The patient was last seen in November, 1962, when she said that she was able to lead an active business life and was not aware of any visual disability. The vision has remained at finger counting in the right eye and $6 / 9$ in the left. The right disc appears pale and atrophic and the right visual field continues to show a centro-caecal scotoma to $100 / 2000$ although the peripheral field is now full to a $2 \mathrm{~mm}$. object (Fig. 5, overleaf). The rest of the neurological examination is normal and $x$ rays of the skull and optic foramina show no evidence of recurrence.

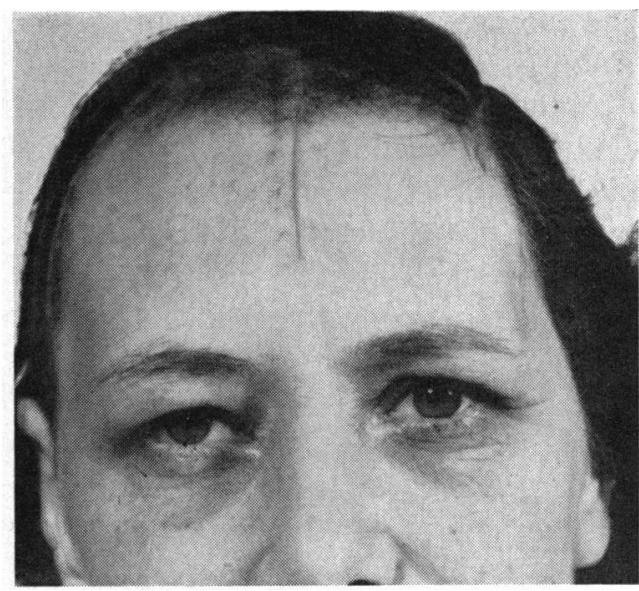

FIG. 4.-Photographs of patient 2 weeks after operation to show incision.

\section{Discussion}

This case is of interest from several points of view and these will now be considered.

(1) Intra-orbital Meningioma. - Though many cases of intra-orbital tumours had been recorded before 1937, Cushing and Eisenhardt (1938) were unable to find any proven case of a purely intra-orbital meningioma because most of them had an intracranial origin or extension. The first recorded case is probably attributable to Friedenwald (1937) or Coston (1936). Many cases have now been recorded, and Reese (1951) found 21 in a series of 251 orbital tumours, an incidence of 8 per cent. 


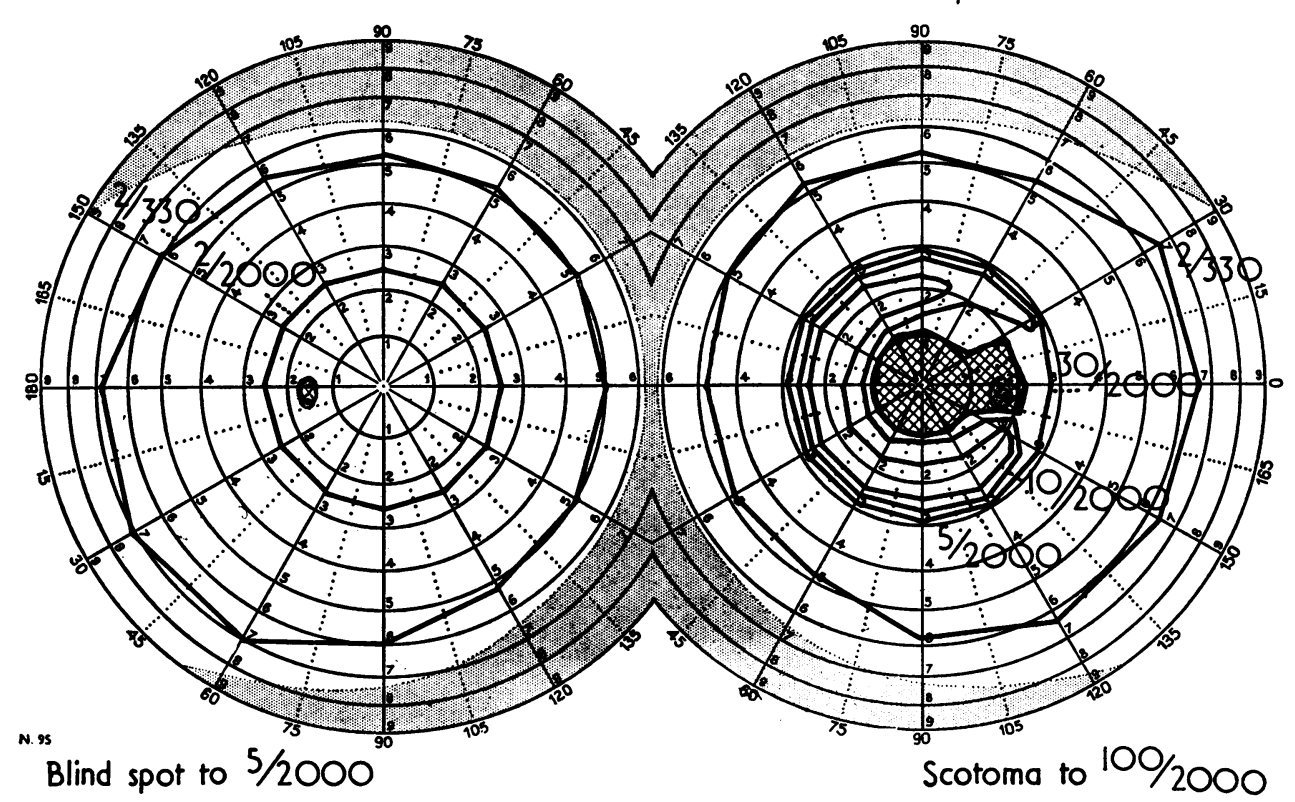

Fig. 5.-Visual fields 10 years after operation.

The average age at onset appears to be the third decade when the tumours are slowly progressive and rarely involve the optic nerve or the globe. However, intra-orbital meningiomata tend to pass intracranially through the optic canal and vice versa (Dunn and Walsh, 1956). Hence Reese (1951) concluded that it is well to assume that all intra-orbital meningiomata involve both the orbital and intracranial portions of the optic nerve sheath. The symptoms are dependent on the precise position of the tumour, visual failure being the commonest symptom in most cases. Proptosis is also common and almost all patients show one or both of these features (Forrest, 1949; Craig and Gogela, 1949). The cases that present solely with visual failure are usually those in which the tumour arises from the region of the optic canal. Thus three of the seventeen patients with intra-orbital meningioma recorded by Craig and Gogela (1949) complained of visual failure without proptosis, and the failure was found to be due to a meningioma arising from within the optic canal.

(2) Relation of the Tumour to the Visual Field.-The precise cause of the centrocaecal scotoma in cases of optic nerve compression still remains a matter of conjecture. For many years it has been postulated that the more specialized macular fibres are more susceptible to compression than the peripheral fibres. This has been attributed to direct pressure or to a relatively poor blood supply or to a combination of both (Behr, 1935). The literature on visual field defects in optic nerve compression was reviewed by Chamlin (1957), who stressed the frequency of peripheral field defects. Meadows (1949) stated that "the field defect in early cases may consist of a central scotoma, but by the time the patient sees his medical advisers there is often a gross central scotomatous defect breaking through to the periphery".

It is therefore of interest to relate the site of this small tumour to the changes observed in the visual fields. The arrangement of the fibres in the intracanalicular 
portion of the optic nerve is such that the macular fibres are centrally placed and the fibres from the retinal periphery lie surrounding them (Duke-Elder, 1961). The visual field in this case demonstrates a predominantly scotomatous defect and, in the absence of any marked infero-nasal defect in the peripheral field which would correspond to the supero-lateral position of the tumour, the macular sensitivity is more readily explained on a vascular basis. It has been shown that there is no axial artery in the intracanalicular portion of the optic nerve, but that the blood supply is by a pre-capillary plexus, the distribution of which is irregular (François, Neetens, and Collette, 1958). Thus the field changes in this case conform with those described in other cases of optic nerve compression (Traquair, 1946; Hughes, 1958), and there is evidence that the scotoma is extending peripherally, though the breakthrough is not occurring in the peripheral fibres directly related to the site of the tumour. A vascular basis for these changes is therefore suggested.

(3) Surgical Intervention in Cases of Unilateral Visual Failure.-This case is presented not with a view to discussing the difficulties of diagnosis of unilateral visual failure, but rather to emphasize the importance of surgical exploration in some of these cases. The main condition with which optic nerve compression may be confused is "retrobulbar neuritis". Indeed these conditions may be so similar that Larsson and Nord (1947) and Woods (1948) stated that a typical retrobulbar neuritis may be caused by pressure of an intracranial lesion upon the optic nerve. Furthermore, some cases of retrobulbar neuritis may not show signs of recovery for 2 or 3 years (Walsh, 1956; Carroll, 1956). However, most cases show some alleviation of symptoms within 2 to 3 months and if this fails to occur further investigations are necessary.

Optic nerve compression may occur in the orbit, the optic canal, or within the cranium, and it is with the two latter conditions that we are here concerned, for these may cause unilateral visual failure without other ocular features, such as proptosis or cranial nerve palsies. Intracranial lesions, however are usually demonstrable, either by carotid arteriography or by an air encephalogram. The intracanalicular lesions may give negative results on radiological examination, though sometimes the optic foramen may be distorted or sclerotic. Hence it should be concluded that the investigation of a case of unilateral visual failure if steadily progressive should include craniotomy, even when other investigations are negative. Furthermore, the exploration should include not only the intracranial part of the optic nerves but the intracanalicular portion as well.

\section{Summary}

The case is recorded of a 39-year-old woman with a 7-month history of progressive visual deterioration in the right eye. The visual field showed a centro-caecal scotoma but all other significant investigations were negative. At craniotomy a small meningioma was removed from the intracanalicular portion of the optic nerve and there has been no recurrence over a 10-year period.

Various aspects of the case are discussed, including the frequency of meningiomata, the relation of the tumour to the visual fields, and the indications for exploratory craniotomy. 
We should like to thank Dr. J. N. Corsellis and the Neuropathology Department, Maudsley Hospital (Prof. P. Daniel), for restaining and reporting on the microscopical sections, Dr. R. D. Hoare for the radiological reports, and Miss S. Treadgold of the Medical Illustration Department and Mr. C. E. Engel of the Photographic Department, Guy's Hospital, for their assistance with the illustrations.

\section{REFERENCES}

BeHr, C. (1935). v. Graefes Arch. Ophthal., 134, 227.

Carroll, F. D. (1946). Trans. Amer. Acad. Ophthal. Otolaryng., 60, 7.

Coston, T. O. (1936). Arch. Ophthal. (Chicago), 15, 696.

Chamlin, M. (1957). A.M.A. Arch. Ophthal., 58, 37.

Craig, W. McK., and Gogela, L. J. (1949). Amer. J. Ophthal., 32, 1663.

Cushing, H., and EISENHARDT, L. (1938). "Meningiomas". Thomas, Springfield, Ill.

DUKE-ELdER, S. (1961). "System of Ophthalmology", vol. 2, p. 644. Kimpton, London.

Dunn, S. N., and WalSh, F. B. (1956). A.M.A. Arch. Ophthal., 56, 702.

FrIEDENWALD, J. (1937). Cited by Cushing and Eisenhardt (1938), p. 297.

Forrest, A. W. (1949). Arch. Ophthal. (Chicago), 41, 198.

François, J., Neetens, A., and Collette, J. M. (1958). Brit. J. Ophthal., $42,65$.

Hughes, B. (1958). Ibid., 42, 106.

REESE, A. B. (1951). "Tumors of the Eye". Hoeber, New York.

LARSSON, S., and Nord, B. (1947). Nord. Med., 34, 1059.

Meadows, S. P. (1949). Proc. roy. Soc. Med., 42, 1017.

Mooney, A. J., and McConnel l, A. A. (1949). J. Neurol. Neurosurg. Psychiat., 12, 205.

Traquair, H. M. (1946). "An Introduction to Clinical Perimetry", 5th ed. Kimpton, London.

Walsh, F. B. (1956). Trans. Amer. Acad. Ophthal. Otolaryng., 60, 39, 62, 82.

Woods, A. C. (1948). Amer. J. Ophthal., 31, 1053. 